Published in final edited form as:

Curr Opin Nephrol Hypertens. 2011 May ; 20(3): 263-270. doi:10.1097/MNH.0b013e3283456731.

\title{
Pathogenesis of ANCA Vasculitis
}

\author{
J. Charles Jennette, M.D. [Brinkhous Distinguished Professor and Chair], \\ Department of Pathology and Laboratory Medicine, University of North Carolina at Chapel Hill
}

Ronald J. Falk, M.D. [Doc Thurston Professor and Chief], and

Division of Nephrology and Hypertension, Department of Medicine, University of North Carolina at Chapel Hill

Adil Hussein Gasim, M.D. [Clinical Instructor]

Department of Pathology and Laboratory Medicine, University of North Carolina at Chapel Hill

\begin{abstract}
Purpose of Review-Anti-neutrophil cytoplasmic autoantibodies (ANCA) are associated with vasculitis. Current therapy involves administration of toxic therapy that is not optimally effective. The review will summarize evidence for the pathogenicity of ANCA, which will suggest possible strategies for improving treatment.
\end{abstract}

Recent Findings-Pauci-immune small vessel vasculitis is associated with antibodies against myeloperoxidase (MPO-ANCA) and proteinase 3 (PR3-ANCA). One research group has reported a high frequency of autoantibodies against lysosomal-associated membrane protein 2 (LAMP-2) in patients with MPO-ANCA or PR3-ANCA. Epigenetic dysregulation appears to be the basis for increased MPO and PR3 neutrophil gene expression in ANCA disease. Release of neutrophil extracellular traps (NETS) may be involved in initiating the ANCA autoimmune response and causing vessel injury. Generation of C5a by alternative pathway activation is involved in pathogenesis in mouse models. Intervention strategies in mice that target antigens, antibodies and inflammatory signaling pathways may translate into novel therapies. Animal models of LAMPANCA and PR3-ANCA disease have been proposed. Molecular mimicry and responses to complementary peptides may be initiating events for ANCA. T cells, including regulatory $\mathrm{T}$ cells, have been implicated in the origin and modulation of the ANCA, as well as in the induction of tissue injury.

Summary-Our basic understanding of the origins and pathogenesis of ANCA disease is advancing. This deeper understanding already has spawned novel therapies that are being investigated in clinical trials. This brief review shows that there are more questions than answers, and new questions are emerging faster than existing questions are being answered.

Contact Information: J. Charles Jennette, M.D., Brinkhous Distinguished Professor and Chair, Department of Pathology and Laboratory Medicine, 308 Brinkhous-Bullitt Building, University of North Carolina, Chapel Hill, NC 27599-7525, Telephone: 919-966-4676, Fax 919-966-4542, jcj@med.unc.edu.

Publisher's Disclaimer: This is a PDF file of an unedited manuscript that has been accepted for publication. As a service to our customers we are providing this early version of the manuscript. The manuscript will undergo copyediting, typesetting, and review of the resulting proof before it is published in its final citable form. Please note that during the production process errors may be discovered which could affect the content, and all legal disclaimers that apply to the journal pertain. 


\section{Keywords}

Vasculitis; Pathogenesis; Antineutrophil Cytoplasmic Autoantibodies; ANCA

\section{Introduction}

Anti-neutrophil cytoplasmic autoantibodies (ANCA) are associated with a distinctive group of necrotizing small vessel vasculitides that typically have a paucity of vascular deposition of immunoglobulin and complement (1). This distinguishes ANCA disease from disease caused by anti-glomerular basement membrane antibodies (anti-GBM disease) and classic immune complex disease, both of which have conspicuous deposition of immunoglobulin in vessel walls. However, even though pauci-immune ANCA disease does not have much immunoglobulin in vessel walls, there is substantial evidence supporting a pathogenic role for ANCA. Pauci-immune necrotizing and crescentic glomerulonephritis is a frequent component of ANCA disease. The pathologic and immunohistologic features of glomerulonephritis is indistinguishable in the different clinicopathologic variants of ANCA disease, including Wegener's granulomatosis (granulomatosis with polyangiitis), microscopic polyangiitis, Churg-Strauss syndrome (allergic granulomatosis with polyangiitis), or renal-limited pauci-immune necrotizing and crescentic glomerulonephritis. Two major target antigens for ANCA are myeloperoxidase (MPO) and proteinase 3 (PR3), which are proteins in the primary granules of neutrophils and the lysosomes of monocytes. More recently, autoantibodies against human lysosomal-associated membrane protein 2 (LAMP-2) have been reported in patients with either MPO-ANCA or PR3-ANCA $(2,3)$. This review will summarize evidence that supports a pathogenic role for ANCA.

\section{Clinical observations supporting pathogenicity of ANCA}

Based solely on pathologic findings, in 1954 Godman and Churg proposed that Wegener's granulomatosis, microscopic polyangiitis, and Churg Strauss syndrome might have a common pathogenesis (4). The close association of circulating ANCA with these diseases supports the relatedness of these clinicopathologic syndromes and suggests a common pathogenesis. Additional clinical observations that support but do not prove a pathogenic role for ANCA are the correlation of ANCA titers with response to treatment, the value of anti-B cell therapy and plasma exchange in treatment $(5,6)$, the induction of pauci-immune small vessel vasculitis in patients who develop ANCA secondary to drug treatment $(7,8)$, and the correlation of ANCA disease with higher levels of ANCA target antigens on the surface of circulating neutrophils $(9,10)$. There also is one intriguing report of a neonate who developed pulmonary and renal disease after transplacental passage of MPO-ANCA IgG from a mother with microscopic polyangiitis (11). This raises the possibility that the infant developed ANCA disease, however, no pathologic confirmation was obtained and no additional corroborating cases have been reported.

\section{In vitro observations supporting pathogenicity of ANCA}

Many in vitro studies demonstrate mechanisms by which ANCA could cause vasculitis in vivo (Figure 1). For example, incubation of ANCA IgG with neutrophils that have been 
primed with cytokines causes the release of destructive granule enzymes and toxic reactive oxygen radicals (12). This increases the expression of ANCA antigens on the surface of neutrophils where they can interact with ANCA to cause neutrophil activation (13). ANCA activation of neutrophils is mediated by both engagement of Fc receptors by immunoglobulin bound to MPO or PR3 $(14,15)$ as well as by the binding of ANCA Fab'2 to ANCA antigens on the surface of neutrophils $(16,17)$. ANCA bind not only to ANCA antigens at the surface of neutrophils and monocytes, but also to ANCA antigens adsorbed onto endothelial cells and other tissue constituents at sites of injury (17). Leukocytes activated by ANCA in vitro release mediators that are injurious to endothelial cells (18-20). In vitro activation of neutrophils by ANCA also stimulates the release of neutrophil extracellular traps (NETS) that contain chromatin and granule proteins including MPO and PR3 $(21,22)$. NETS also were observed in glomeruli from patients with glomerulonephritis (21). NETS not only can trigger damage to endothelial cells, but may be involved in initiating or perpetuating the ANCA autoimmune response by presenting ANCA antigens to the immune system (21).

Recent studies have shed light on mechanisms by which ANCA antigens are displayed on the surface of neutrophils. Abdgawad et al. observed a link between the increased membrane expression of PR3 on neutrophils and expression of CD177 (NB1 glycoprotein) (23). Jerke et al also observed the linkage of PR3 with CD177 and found evidence that this complex interacts with the complement receptor Mac-1 to induce neutrophil activation (24). The interaction of PR3 with associated molecules may play an important role not only in the activation of neutrophils by PR3-ANCA, but also in the presentation of PR3 as an antigen to the immune system (25).

As mentioned earlier, ANCA disease is associated with higher levels of ANCA target antigens on the surface of circulating neutrophils $(9,10)$. In addition, patients with ANCA disease have aberrant transcription of PR3 and MPO genes in circulating neutrophils, which normally is shut off before neutrophils are released from the bone marrow (26). Ciavatta et al have discovered that this aberrant overexpression of genes for ANCA target antigens (MPO and PR3) in ANCA disease patients is the result of disturbed epigenetic regulation (27). An understanding of the expression and display of ANCA autoantigens may help understand both the genesis of the autoimmune response and the pathogenic interaction with ANCA, which could point to novel therapies.

\section{Animal models of ANCA disease}

Several animal models of ANCA disease have been described (28). Intravenous injection of anti-MPO IgG into mice causes a pauci-immune necrotizing glomerulonephritis and a pauciimmune systemic small vessel vasculitis that is pathologically identical to human ANCA disease (29). Another mouse model has been produced by transplanting wild type $(\mathrm{Mpo}+/+)$ bone marrow cells into irradiated MPO knockout (Mpo-/-) mice or vice versa (30). Bone marrow-derived cells are sufficient and necessary for anti-MPO to cause glomerulonephritis and vasculitis in this model because chimeric Mpo-/- mice with circulating MPO+/+ neutrophils develop glomerulonephritis, whereas chimeric $\mathrm{Mpo}+/+$ mice with circulating MPO-/- neutrophils do not (29). Disease in mouse models is enhanced by systemic 
administration of proinflammatory factors (31), ameliorated by anti-TNF-alpha (31), and prevented by the depletion of neutrophils (32) or by inactivation of the alternative pathway of complement activation $(33,34,35)$. In vitro, ANCA-activated neutrophils release factors that activate complement $(33,35)$. Activation of complement generates C5a, which is a potent neutrophil chemoattractant and activator. Recent studies implicate the engagement of C5a receptors as an important event in the induction of disease in these mouse models $(34,35)$.

These observations raise the possibility that therapy aimed at blocking complement activation might be feasible in human ANCA disease. Two recent studies using mouse models of MPO-ANCA disease suggest even more novel treatment strategies. Schreiber at al found that phosphoinositol 3 kinase-gamma isoform (PI3Kgamma), which is required for a number of signaling pathways involved in neutrophil activation, plays a pivotal role in disease induced by anti-MPO in mice (36). PI3Kgamma deficient mice were protected against disease induction, and a PI3Kgamma inhibitor prevented disease induction in vivo and blocked activation of neutrophils by ANCA in vitro. Van Timmeren et al used a different strategy to attenuate disease induction by anti-MPO IgG (37). They used a bacterial endoglycosidase to treat the pathogenic anti-MPO IgG, which abrogates Fc receptor engagement and complement activation by the $\mathrm{IgG}$ but does not interfere with antigen binding. The hydrolyzed anti-MPO IgG was ineffective in vitro in activating neutrophils and did not cause disease when injected into mice. These studies suggest that treatments that modify either ANCA antibodies or effector neutrophils might be effective in ANCA disease.

A rat model of ANCA disease can be induced by immunizing rats with human MPO, which induces anti-MPO antibodies that cross react with human and rat MPO (38). As in the mouse model (31), anti-rat TNF antibodies ameliorate disease in this rat model (39). Of interest with respect to these observations are recent clinical studies that suggest a role for anti-TNF therapy in ANCA disease patients $(40,41)$.

Although there are several credible animal models of MPO-ANCA disease, there has been less success with producing a compelling model of PR3-ANCA disease, which has led some to question the pathogenicity of anti-PR3 antibodies and to invoke other pathogenic mechanisms for PR3-ANCA disease, such T cell mediated inflammation. Until recently, the most promising model was described by Pfister at al who produced antibodies against recombinant murine PR3 mice deficient in PR3 and elastase (42). Mice injected with these anti-PR3 antibodies developed enhanced subcutaneous inflammation at sites injected with tumor necrosis factor alpha, but did not develop glomerulonephritis or vasculitis. In 2009, Primo et al. reported a more convincing model (43). They immunized autoimmunity prone non-obese diabetic (NOD) mice with recombinant mouse PR3 in complete Freund's adjuvant resulting in high levels of circulating anti-PR3. No disease developed, however, when splenocytes from these immunized mice were transferred into immune deficient NODsevere combined immunodeficiency (SCID) mice, the mice developed necrotizing glomerulonephritis and vasculitis. Control mice that received splenocytes from nonimmunized mice developed no disease, supporting a specific effect caused by PR3 immunization. This is a promising model, but additional studies are required to confirm and elucidate the mechanism underlying the glomerulonephritis and vasculitis. In an ex vivo rat 
model, Hattar et al. used isolated rat lungs to investigate the pathogenicity of anti-PR3 antibodies (44). Rat lungs were perfused with human neutrophils primed with TNF and monoclonal anti-PR3 antibodies. This induced marked weight gain in the lungs due to increased capillary permeability and edema, but no overt vasculitis in the lungs. Again, this is an interesting model, but more studies are required to understand the underlying mechanisms and their relevane to human ANCA disease.

As mentioned earlier, antibodies to LAMP-2 have been reported to occur in high frequency in patients with active PR-ANCA and MPO-ANCA disease $(2,3)$. Kain et al. also reported evidence that anti-LAMP-2 antibodies are pathogenic in rats (3). Anti-LAMP-2 antibodies caused pauci-immune necrotizing glomerulonephritis when injected into rats. As discussed below, cross reactive antibodies induced by immunization with a bacterial protein that has homology to LAMP-2 also caused disease in rats. These observations are extremely important because they rats the possibility that antibodies to LAMP-2 are as important if not more important than antibodies to MPO or PR3 in the pathogenesis of ANCA disease. However, no other laboratory has yet reported confirmation of either the frequency of antiLAMP-2 antibodies in patients or the pathogenicity of these antibodies in animal models.

\section{Origin of the ANCA autoimmune response}

So far in this review, the focus had been on the pathogenesis of disease in patients who have circulating ANCA. Another important issue is the origin and persistence of the autoimmune response that leads to the pathogenic events. Two mechanisms that have been proposed for the origin of the ANCA autoimmune response are molecular mimicry of the autoantigen by a bacterial peptide (3) and induction of autoimmunity through an immune response to the complementary peptide of the autoantigen that secondarily results in antibodies against the autoantigen (45).

Kain et al. have proposed that molecular mimicry of LAMP-2 by a the bacterial adhesin FimH can induce circulating anti-FimH antibodies that cross react with LAMP-2, which can cause pauci-immune glomerulonephritis and small vessel vasculitis (3). A LAMP-2 peptide has 100\% homology to FimH. Rats immunized with FimH developed antibodies to rat and human LAMP-2, and developed pauci-immune necrotizing glomerulonephritis. The authors thus postulate that infection by fimbriated bacteria bearing FimH induces an immune response that cross reacts with LAMP-2 resulting in the mediation of pauci-immune necrotizing glomerulonephritis and vasculitis. This is a paradigm shifting concept that undoubtedly will result in follow up studies from many laboratories. To date, no confirmatory reports have been published.

Another novel theory for induction of the ANCA autoimmune response postulates that the initial immune response is against an epitope that is on anti-sense peptide (complementary autoantigen peptide) or a mimic of an anti-sense peptide rather than against a sense autoantigen peptide (Figure 1) $(45,46)$. Patients with PR3-ANCA disease have not only circulating antibodies against sense PR3 peptides but also a separate set of antibodies against antisense complementary PR3 peptides (anti-cPR3). Theoretically, an immune response to a complementary PR3 peptide produces anti-cPR3 antibodies, which in turn cause the 
development of anti-idiotypic antibodies that recognize not only the idiotope on the anticPR3 antibodies but also the portion of the PR3 molecule to which the peptide is complementary. The cPR3 peptide could arise endogenously from transcription of PR3 antisense, or could be introduced exogenously, for example as a component of an infectious microorganism that has a peptide that mimics cPR3. Interestingly, several pathogens that are associated with the development of PR3-ANCA (including Ross river virus, Staphylococcus aureus and Entamoeba histolytica) have constituent mimics of cPR3 (45).

An interesting outgrowth of the theory of autoantigen complementarity is the identification of autoantibodies with dual reactivity to plasminogen and complementary PR3 in patients with ANCA disease $(47,48)$. Further, patients with anti- plasminogen antibodies are at increased risk for thrombotic complications. Plasminogen has an epitope that also occurs in cPR3, thus suggesting that thye arise secondary to molecular mimicry (47). Berden at al. noted that patients with anti-plasminogen antibodies had a greater percentages of glomeruli with fibrinoid necrosis and cellular crescents, and had more severe renal insufficiency, suggesting a possible role in the pathogenesis of glomerulonephritis (48).

The development of ANCA can be associated with persistent bacterial or viral infections, especially bacterial endocarditis $(49,50)$. In this setting, ANCA may not result in the induction of glomerulonephritis or vasculitis, and appropriate therapy should be directed at eliminating the infection. Clues that a patient may have an infection associate ANCA are dual PR3-ANCA and MPO-ANCA positivity, and concurrence of other autoantibodies, such as anti-cardiolipin antibodies or cryoglobulins (50). Patients with non-pathogenic infectionassociated ANCA may have glomerulonephritis caused by infection-induced immune complex glomerulonephritis (e.g. cryoglobulinemic glomerulonephritis) even though they do not have ANCA disease.

Drugs and other environmental factors may induce an ANCA autoimmune response. Silica is a risk factor for ANCA disease $(51,52)$. ANCA disease can be caused by drugs, including propylthiouracil, hydralazine, D-penicillamine, allopurinol, minocycline and anti-TNF agents $(7,8,53)$. Visavachaipan recently reviewed their experience seven patients with Graves' disease who received propylthiouracil and developed ANCA disease (53).

Proteinuria ranged from 0.49-2.9 gram per day. Mean serum creatinine was $2.05 \mathrm{mg} / \mathrm{dl}$ with creatinine clearance of $44+/-35 \mathrm{ml} / \mathrm{min}$. Renal remission occurred in all patients after propylthiouracil was withdrawn and steroids administered.

\section{Regulation of the ANCA autoimmune response}

Once an ANCA autoimmune response develops, regulation of the response probably is critical in whether or not it will be pathogenic. In fact, Cui et al. have presented evidence that PR3 and MPO 'natural autoantibodies' are present in most if not all health individuals (54). If true, the development of pathogenic ANCA may be the result of Dysregulation of non-pathogenic natural ANCA rather than the development of a totally new autoimmune capability $(54,55)$.

Even if ANCA produced by B-cells are the primary pathogenic factors in cause the acute lesions of ANCA disease, T cells undoubtedly are involved in regulating the genesis, 
persistence and modulation of the ANCA-producing B cell clones, and in regulating the innate inflammatory responses to acute ANCA injury. A number of recent articles address these issues $(56$,

Morgan et al. have demonstrated that patients with Wegener's granulomatosis demonstrated abnormalities in the number and function of regulatory $\mathrm{T}$ cells and this is most pronounced in patients with the most active disease (57). In addition, patients with active ANCA disease who had increased circulating CD4(+) Foxp3(+) cells had a more rapid disease remission. Chavele et al studied MPO-specific T cell reactivity and regulation during disease remission and concluded that MPO-specific $\mathrm{T}$ cell frequencies are regulated during disease remission (58). They also noted that FoxP3 levels were diminished in patients compared with controls. This same group also studied serum IL-17A and IL-23, and the frequency of IL-17producing autoantigen-specific T cells in patients with ANCA disease (59). Serum IL-17A levels were significantly elevated in acute disease compared to healthy controls. Patients with elevated levels of IL-23 compared to those with low IL-23 had more active disease and higher ANCA titers. The authors conclude that the Th17 axis is important in the modulation of ANCA disease. Futher, Lamprecht et al have proposed that modulation of the T-cell responses in tissue, including Th1 and Th17 responses and dysfunctional regulatory T cells, could be responsible for the distinctive aggressive granulomatous inflammation of Wegener's granulomatosis (60). In line with this study, Wilde et al. have emphasized the importance of evaluating not only circulating $\mathrm{T}$ cells but also tisuue $\mathrm{T}$ cells, especially at sites of injury (61).

To date, there has not been extensive study of the role of T cells in animal models of ANCA disease. One recent study uses a mouse model of autoimmune glomerulonephritis that results from apparent synergy between anti-GBM and anti-MPO antibodies $(62,63)$. In this model, anti-MPO CD4+ T cells appear to act with macrophages to amplify glomerular injury (62). Using this model, Gan et al. also observed that mice deficient in the Th17 effector cytokine IL-17A were nearly completely protected from developing glomerulonephritis (62).

Thus, there is evidence that $\mathrm{T}$ cells are involved in both the genesis and regulation of the ANCA autoimmune response, as well as effector events in ANCA disease.

\section{Conclusions}

Clinical, in vitro experimental and animal model data support a direct pathogenic role for ANCA in the pathogenesis of ANCA disease (Figure 1). In vitro evidence indicates that ANCA IgG can activate neutrophils and monocytes through Fc receptor and Fab'2 binding resulting in adhesion to endothelial cells and release of cytotoxic factors. In vivo animal model evidence indicates that ANCA can cause renal and systemic pauci-immune necrotizing vasculitis that closely resembles human ANCA-associated vasculitis. This evidence is better for anti-MPO than for anti-PR3 antibodies. T cells appear to play important roles in the genesis of the autoimmune response, as well as in the orchestration of tissue injury. The origin and pathogenesis of ANCA disease involves interplay between multiple environmental, genetic and biological processes that initiate the pathogenic 
autoimmune response, cause the acute lesions, and lead to chronic progression of lesions if therapy is not fully effective.

\section{Acknowledgments}

Funding: Some of the research by RJ Falk and JC Jennette was supported by NIH grant PO1 DK058335

\section{References}

1. Falk RJ, Jennette JC. ANCA disease: where is this field heading? J Am Soc Nephrol. 2010; 21:745752. [PubMed: 20395376] A concise review of all aspects of ANCA disease, including comments about the current controversy over the use of Wegener's name as a eponym, and the controversy over LAMP-2 antibodies.

2. Kain R, Matsui K, Exner M, et al. A novel class of autoantigens of anti-neutrophil cytoplasmic antibodies in necrotizing and crescentic glomerulonephritis: the lysosomal membrane glycoprotein h-lamp-2 in neutrophil granulocytes and a related membrane protein in glomerular endothelial cells. J Exp Med. 1995; 181:585-597. [PubMed: 7836914]

3. Kain R, Exner M, Brandes R, et al. Molecular mimicry in pauci-immune focal necrotizing glomerulonephritis. Nat Med. 2008; 14:1088-1096. [PubMed: 18836458]

4. Godman GC, Churg J. Wegener's granulomatosis. Pathology and review of the literature. Arch Pathol Lab Med. 1954; 58:533-553.

5. Falk RJ, Jennette JC. Rituximab in ANCA-associated disease. N Engl J Med. 2010; 363:285-286. [PubMed: 20647204]

6. Szpirt WM, Heaf JG, Petersen J. Plasma exchange for induction and cyclosporine A for maintenance of remission in Wegener's granulomatosis--a clinical randomized controlled trial. Nephrol Dial Transplant. 2011; 26:206-213. [PubMed: 20577017] Clinical evidence that removal of ANCA reduces the induction of injury.

7. Morita S, Ueda Y, Eguchi K. Anti-thyroid drug-induced ANCA-associated vasculitis: a case report and review of the literature. Endocrine Journal. 2000; 47(4):467-470. [PubMed: 11075728]

8. Choi HK, Merkel PA, Walker AM, Niles JL. Drug-associated antineutrophil cytoplasmic antibodypositive vasculitis: prevalence among patients with high titers of antimyeloperoxidase antibodies. Arthritis Rheum. 2000; 43(2):405-413. [PubMed: 10693882]

9. Schreiber A, Busjahn A, Luft FC, Kettritz R. Membrane expression of proteinase 3 is genetically determined. J Am Soc Nephrol. 2003; 14(1):68-75. [PubMed: 12506139]

10. Schreiber A, Luft FC, Kettritz R. Membrane proteinase 3 expression and ANCA-induced neutrophil activation. Kidney Int. 2004; 65(6):2172-2183. [PubMed: 15149330]

11. Schlieben DJ, Korbet SM, Kimura RE, Schwartz MM, Lewis EJ. Pulmonary-renal syndrome in a newborn with placental transmission of ANCAs. Am J Kidney Dis. 2005; 45:758-761. [PubMed: 15806479]

12. Falk RJ, Terrell RS, Charles LA, Jennette JC. Anti-neutrophil cytoplasmic autoantibodies induce neutrophils to degranulate and produce oxygen radicals in vitro. Proc Natl Acad Sci U S A. 1990; 87(11):4115-4119. [PubMed: 2161532]

13. Charles LA, Caldas ML, Falk RJ, Terrell RS, Jennette JC. Antibodies against granule proteins activate neutrophils in vitro. J Leuk Biol. 1991; 50:539-546.

14. Mulder AH, Stegeman CA, Kallenberg CG, et al. Activation of granulocytes by anti-neutrophil cytoplasmic antibodies (ANCA) in Wegener's granulomatosis: a predominant role for the IgG3 subclass of ANCA Autoantibodies developing to myeloperoxidase and proteinase 3 in systemic vasculitis stimulate neutrophil cytotoxicity toward cultured endothelial cells. Clin Exp Immunol. 1992; 141:335-342.

15. Porges AJ, Redecha PB, Kimberly WT, et al. Anti-neutrophil cytoplasmic antibodies engage and activate human neutrophils via Fc gamma RIIa. J Immunol. 1994; 153:1271-1280. [PubMed: 8027554] 
16. Kettritz R, Jennette JC, Falk RJ. Cross-linking of ANCA-antigens stimulates superoxide release by human neutrophils. J Am Soc Nephrol. 1997; 8:386-394. [PubMed: 9071707]

17. Williams JM, Ben Smith A, Hewins P, et al. Activation of the G(i) heterotrimeric G protein by ANCA $\operatorname{IgG~F}\left(\mathrm{ab}^{\prime}\right) 2$ fragments is necessary but not sufficient to stimulate the recruitment of those downstream mediators used by intact ANCA IgG. J Am Soc Nephrol. 2003; 14:661-669. [PubMed: 12595502]

18. Savage CO, Gaskin G, Pusey CD, Pearson JD. Myeloperoxidase binds to vascular endothelial cells, is recognized by ANCA and can enhance complement dependent cytotoxicity. Adv Exp Med Biol. 1993; 336:121-123. [PubMed: 8296599]

19. Ewert BH, Jennette JC, Falk RJ. Anti-myeloperoxidase antibodies stimulate neutrophils to damage human endothelial cells. Kidney Int. 1992; 41:375-383. [PubMed: 1313124]

20. Lu X, Garfield A, Rainger GE, Savage CO, Nash GB. Mediation of endothelial cell damage by serine proteases, but not superoxide released from antineutrophil cytoplasmic antibody-stimulated neutrophils. Arthritis Rheum. 2006; 54:1619-1628. [PubMed: 16646023]

21. Kessenbrock K, Krumbholz M, Schönermarck U, Back W, Gross WL, Werb Z, Gröne HJ, Brinkmann V, Jenne DE. Netting neutrophils in autoimmune small-vessel vasculitis. Nat Med. 2009; 15:623-625. [PubMed: 19448636] The first report that neutrophil extracellular traps (NETS) not only can trigger damage to endothelial cells, but also may be involved in initiating or perpetuating the ANCA autoimmune response by presenting ANCA antigens to the immune system.

22. Gupta AK, Joshi MB, Philippova M, et al. Activated endothelial cells induce neutrophil extracellular traps and are susceptible to NETosis-mediated cell death. FEBS Lett. 2010; 584:3193-3197. [PubMed: 20541553] A useful general review of the pathobiology of neutrophil NETs.

23. Abdgawad M, Gunnarsson L, Bengtsson AA, Geborek P, Nilsson L, Segelmark M, Hellmark T. Elevated neutrophil membrane expression of proteinase 3 is dependent upon CD177 expression. Clin Exp Immunol. 2010; 161:89-97. [PubMed: 20491791] This provides insight into the mechanism by which PR3 is expressed on neutrophil surfaces to be accessible for binding to PR3ANCA.

24. Jerke U, Rolle S, Dittmar G, et al. Complement receptor Mac-1 is an adaptor for NB1 (CD177)mediated PR3-ANCA neutrophil activation. J Biol Chem. 2010 [Epub ahead of print]. The signaling pathway by which ligation of PR3 causes neutrophil activation is proposed.

25. Witko-Sarsat V, Reuter N, Mouthon L. Interaction of proteinase 3 with its associated partners: implications in the pathogenesis of Wegener's granulomatosis. Curr Opin Rheumatol. 2010; 22:17. [PubMed: 19881350] The mechanisms by which ligation of PR3 causes neutrophil activation is explained.

26. Yang JJ, Pendergraft WF, Alcorta DA, et al. Circumvention of normal constraints on granule protein gene expression in peripheral blood neutrophils and monocytes of patients with antineutrophil cytoplasmic autoantibody-associated glomerulonephritis. J Am Soc Nephrol. 2004; 15:2103-2114. [PubMed: 15284296]

27. Ciavatta DJ, Yang J, Preston GA, et al. Epigenetic basis for aberrant upregulation of autoantigen genes in humans with ANCA vasculitis. J Clin Invest. 2010; 120:3209-3219. [PubMed: 20714105] The aberrant overexpression of genes for ANCA target antigens (MPO and PR3) in ANCA disease is attributed to disturbed epigenetic regulation. This could explain the genesis of the autoimmune response and/or mechanism for increased antigen availability for pathogenic interactions with ANCA.

28. Jennette JC, Xiao H, Falk R, Gasim AM. Experimental models of vasculitis and glomerulonephritis induced by antineutrophil cytoplasmic autoantibodies. Contrib Nephrol. 2011; 169:211-220. [PubMed: 21252521] A review of animal models of ANCA disease.

29. Xiao H, Heeringa P, Hu P, et al. Antineutrophil cytoplasmic autoantibodies specific for myeloperoxidase cause glomerulonephritis and vasculitis in mice. J Clin Invest. 2002; 110:955963. [PubMed: 12370273]

30. Schreiber A, Xiao H, Falk RJ, Jennette JC. Bone Marrow-Derived Cells Are Sufficient and Necessary Targets to Mediate Glomerulonephritis and Vasculitis Induced by AntiMyeloperoxidase Antibodies. J Am Soc Nephrol. 2006; 7:3355-3364. [PubMed: 17108314] 
31. Huugen D, Xiao H, van Esch A, et al. Aggravation of anti-myeloperoxidase antibody-induced glomerulonephritis by bacterial lipopolysaccharide: role of tumor necrosis factor-alpha. Am J Pathol. 2005; 167:47-58. [PubMed: 15972951]

32. Xiao H, Heeringa P, Liu Z, Huugen D, Hu P, Maeda N, Falk RJ, Jennette JC. The role of neutrophils in the induction of glomerulonephritis by anti-myeloperoxidase antibodies. Am $\mathrm{J}$ Pathol. 2005; 167:39-45. [PubMed: 15972950]

33. Xiao H, Schreiber A, Heeringa P, Falk RJ, Jennette JC. Alternative complement pathway in the pathogenesis of disease mediated by antineutrophil cytoplasmic autoantibodies. Am J Pathol. 2007; 170:52-64. [PubMed: 17200182]

34. Huugen D, van Esch A, Xiao H, et al. Inhibition of complement factor C5 protects against antimyeloperoxidase antibody-mediated glomerulonephritis in mice. Kidney Int. 2007; 71:646-654. [PubMed: 17299525]

35. Schreiber A, Xiao H, Jennette JC, Schneider W, Luft FC, Kettritz R. C5a receptor mediates neutrophil activation and ANCA-induced glomerulonephritis. J Am Soc Nephrol. 2009; 20:289_ 298. [PubMed: 19073822]

36. Schreiber A, Rolle S, Peripelittchenko L, et al. Phosphoinositol 3-kinase-gamma mediates antineutrophil cytoplasmic autoantibody-induced glomerulonephritis. Kidney Int. 2010; 77:118128. [PubMed: 19907415] Reports that PI3Kgamma deficient mice are protected against disease induction, and that treatment with a PI3Kgamma inhibitor prevented disease induction. This has implications for novel therapies.

37. van Timmeren MM, van der Veen BS, Stegeman CA, Petersen AH, Hellmark T, Collin M, Heeringa P. IgG glycan hydrolysis attenuates ANCA-mediated glomerulonephritis. J Am Soc Nephrol. 2010; 21:1103-1114. [PubMed: 20448018] This interesting observations shows that modifications in the Fc region of pathogenic autoantibodies can influence pathogenicity by blocking effector functions, such as complement activation and $\mathrm{Fc}$ receptor engagement.

38. Little MA, Smyth CL, Yadav R, et al. Antineutrophil cytoplasm antibodies directed against myeloperoxidase augment leukocyte-microvascular interactions in vivo. Blood. 2005; 106:2050 2058. [PubMed: 15933057]

39. Little MA, Bhangal G, Smyth CL, et al. Therapeutic effect of anti-TNF-alpha antibodies in an experimental model of anti-neutrophil cytoplasm antibody-associated systemic vasculitis. J Am Soc Nephrol. 2006; 17:160-169. [PubMed: 16306166]

40. Morgan MD, Drayson MT, Savage CO, Harper L. Addition of infliximab to standard therapy for ANCA-associated vasculitis. Nephron Clin Pract. 2010; 117:c89-c97. [PubMed: 20693809] Shows that monoclonal antibody against tumor necrosis factor alpha is beneficial in treating human ANCA disease. This is in accord with observations on the importance of TNF in the pathogenesis of animal models of ANCA disease.

41. Laurino S, Chaudhry A, Booth A, et al. Prospective study of TNF alpha blockade with adalimumab in ANCA-associated systemic vasculitis with renal involvement. Nephrol Dial Transplant. 2010; 25:3307-3314. [PubMed: 20368305] Shows that monoclonal antibody against tumor necrosis factor alpha is beneficial in treating human ANCA disease. This is in accord with observations on the importance of TNF in the pathogenesis of animal models of ANCA disease.

42. Pfister H, Ollert M, Fröhlich LF, et al. Antineutrophil cytoplasmic autoantibodies against the murine homolog of proteinase 3 (Wegener autoantigen) are pathogenic in vivo. Blood. 2004; 104:1411-1418. [PubMed: 15150076]

43. Primo VC, Marusic S, Franklin CC, et al. Anti-PR3 immune responses induce segmental and necrotizing glomerulonephritis. Clin Exp Immunol. 2010; 159:327-337. [PubMed: 20015271] These investigators report the most convincing animal model yet of PR3 ANCA disease. They immunized autoimmunity prone non-obese diabetic (NOD) mice with recombinant mouse PR3 in Freund's adjuvant. Transfer of splenocytes from these animals immune deficient NOD-severe combined immunodeficiency (SCID) mice resulted in development of necrotizing glomerulonephritis and vasculitis.

44. Hattar K, Oppermann S, Ankele C, et al. c-ANCA-induced neutrophil-mediated lung injury: a model of acute Wegener's granulomatosis. Eur Respir J. 2010; 36:187-195. [PubMed: 20032014] In this putative ex vivo model of PR3 ANCA disease, rat lungs were perfused with human 
neutrophils primed with TNF and monoclonal anti-PR3 antibodies. This induced marked edema but no overt vasculitis.

45. Pendergraft WF III, Preston GA, Shah RR, Tropsha A, Carter CW Jr, Jennette JC, et al. Autoimmunity is triggered by cPR-3(105-201), a protein complementary to human autoantigen proteinase-3. Nat Med. 2004; 10(1):72-79. [PubMed: 14661018]

46. Hewins P, Belmonte F, Charles Jennette J, et al. Longitudinal studies of patients with ANCA vasculitis demonstrate concurrent reactivity to complementary PR3 protein segments cPR3m and cPR3C and with no reactivity to cPR3N. Autoimmunity. 2010 [Epub ahead of print]. This study confirms and extends the observation of antibodies against both the sense and anti-sense (complementary) PR3 peptides in PR3-ANCA disease patients, which supports the theory that complementary peptides may induce autoimmune responses.

47. Bautz DJ, Preston GA, Lionaki S, et al. Antibodies with dual reactivity to plasminogen and complementary PR3 in PR3-ANCA vasculitis. J Am Soc Nephrol. 2008; 19:2421-2429. [PubMed: 18701607]

48. Berden AE, Nolan SL, Morris HL, et al. Anti-plasminogen antibodies compromise fibrinolysis and associate with renal histology in ANCA-associated vasculitis. J Am Soc Nephrol. 2010; 21:2169_ 2179. [PubMed: 20847144] This study confirms the presence of anti-plasminogen antibodies in patients with ANCA disease. In addition to confirming this as a risk factor for thrombosis, the finding adds additional support to the role of antibody responses to complementary peptides in autoimmune responses.

49. Bell EK, Chugh SS, Cook WJ. A case of infection-associated antiproteinase-3-negative cytoplasmic antineutrophil cytoplasmic antibody pauci-immune focal necrotizing glomerulonephritis. Nephrol Dial Transplant. 2010; 25:3119-3123. [PubMed: 20566570] Sheds light on the relationship between ANCA and persistent infections, and suggests the presence of atypical specificities in this setting.

50. Bonaci-Nikolic B, Andrejevic S, Pavlovic M, Dimcic Z, Ivanovic B, Nikolic M. Prolonged infections associated with antineutrophil cytoplasmic antibodies specific to proteinase 3 and myeloperoxidase. Diagnostic and therapeutic challenge. Clin Rheumatol. 2010; 29:893-904. [PubMed: 20306213] A good review of the association of ANCA with infections. Points out that clues dual PR3-ANCA and MPO-ANCA positivity, and concurrence of other autoantibodies, such as anti-cardiolipin antibodies or cryoglobulins, points toward a possible underlying infection as the cause for ANCA.

51. Hogan SL, Satterly KK, Dooley MA, et al. Silica exposure in antineutrophil cytoplasmic autoantibody-associated glomerulonephritis and lupus nephritis. J Am Soc Nephrol. 2001; 12:134142. [PubMed: 11134259]

52. Rihoza Z, Maixnerova D, Jancova E, et al. Silica and asbestos exposure in ANCA-associated vasculitis with pulmonary involvement. Ren Fail. 2005; 27:605-608. [PubMed: 16153001]

53. Visavachaipan N, Ong-Ajyooth L, Chanchairujuira T, Parichatikanond P, Choensuchon B. Clinical features and outcomes in patient with antineutrophil cytoplasmic autoantibody-positive glomerulonephritis associated with propylthiouracil treatment in Siriraj Hospital. J Med Assoc Thai. 2010; 93(Suppl 1):S139-S146. [PubMed: 20364568] An informative case series.

54. Cui Z, Zhao MH, Segelmark M, Hellmark T. Natural autoantibodies to myeloperoxidase, proteinase 3, and the glomerular basement membrane are present in normal individuals. Kidney Int. 2010; 78:590-597. [PubMed: 20592714] This is a well done study showing that 'natural autoantibodies' against PR3 and MPO are present in most if not all health individuals is sensitive methods are used for detection. This has importan conceptual implications fro ANCA disease and autoimmunity in general.

55. Jennette JC, Falk RJ. The rise and fall of horror autotoxicus and forbidden clones. Kidney Int. 2010; 78:533-555. 2010. [PubMed: 20805814] An editorial focused on natural autoantibodies in general.

56. Free ME, Falk RJ. IL-17A in experimental glomerulonephritis. Where does it come from? J Am Soc Nephrol. 2010; 21:885-886. [PubMed: 20466743] An editorial commentary focused on IL-17 and autoiimunity.

57. Morgan MD, Day CJ, Piper KP, Khan N, Harper L, Moss PA, Savage CO. Patients with Wegener's granulomatosis demonstrate a relative deficiency and functional impairment of T-regulatory cells. 
Immunology. 2010; 130:64-73. [PubMed: 20113371] The observed abnormalities in the number and function of regulatory $\mathrm{T}$ cells in ANCA disease patients has important implications about the pathogenesis and treatment of ANCA disease.

58. Chavele KM, Shukla D, Keteepe, et al. Regulation of myeloperoxidase-specific T cell responses during disease remission in antineutrophil cytoplasmic antibody-associated vasculitis: the role of Treg cells and tryptophan degradation. Arthritis Rheum. 2010; 62:1539-1548. [PubMed: 20155828] The function of regulatory T cells in ANCA disease patients has important implications about the pathogenesis and treatment of ANCA disease.

59. Nogueira E, Hamour S, Sawant D, et al. Serum IL-17 and IL-23 levels and autoantigen-specific Th17 cells are elevated in patients with ANCA-associated vasculitis. Nephrol Dial Transplant. 2010; 25:2209-2217. [PubMed: 20100727] As in other autoimmune disease, the IL-17 axis appears to play a role in ANCA disease.

60. Lamprecht P, Wieczorek S, Epplen JT, Ambrosch P, Kallenberg CG. Granuloma formation in ANCA-associated vasculitides. APMIS Suppl. 2009; (127):32-36. [PubMed: 19515137]

61. Wilde B, Thewissen M, Damoiseaux J, et al. T cells in ANCA-associated vasculitis: what can we learn from lesional versus circulating T cells? Arthritis Res The. 2010; 12:204-213. This is a useful review of evidence that $\mathrm{T}$ cells are important in ANCA disease.

62. Ruth AJ, Kitching AR, Kwan RY, et al. Anti-neutrophil cytoplasmic antibodies and effector CD4+ cells play nonredundant roles in anti-myeloperoxidase crescentic glomerulonephritis. J Am Soc Nephrol. 2006; 17:1940-1949. [PubMed: 16769746]

63. Gan PY, Steinmetz OM, Tan DS, et al. Th17 cells promote autoimmune anti-myeloperoxidase glomerulonephritis. J Am Soc Nephrol. 2010; 21:925-931. [PubMed: 20299361] Experimental animal model evidence that the IL-17 axis may play a role in ANCA disease. 


\section{Summary Points}

- Clinical, in vitro experimental and animal model data support a direct pathogenic role for ANCA in the pathogenesis of ANCA disease.

- Neutrophil cytokine priming, antigen presentation cofactors, NETS (neutrophil extracellular traps), Fc receptor engagement, alternative pathway complement activation, and multiple signaling pathways are involved in neutrophil pathogenic activation by ANCA.

- Induction and persistence of the ANCA autoimmune response may involve multiple mechanisms including environmental stimuli (e.g. silica, drugs, and microbial pathogens), dysregulation of granule protein gene expression, autoantigen mimicry, autoantigen complementary (antisense) peptides, and aberrant $\mathrm{T}$ cell regulation.

- Novel treatment strategies can target any of these mechanisms that induce and sustain the autoimmune ANCA response, or that mediate the pathogenic events induced by ANCA. 


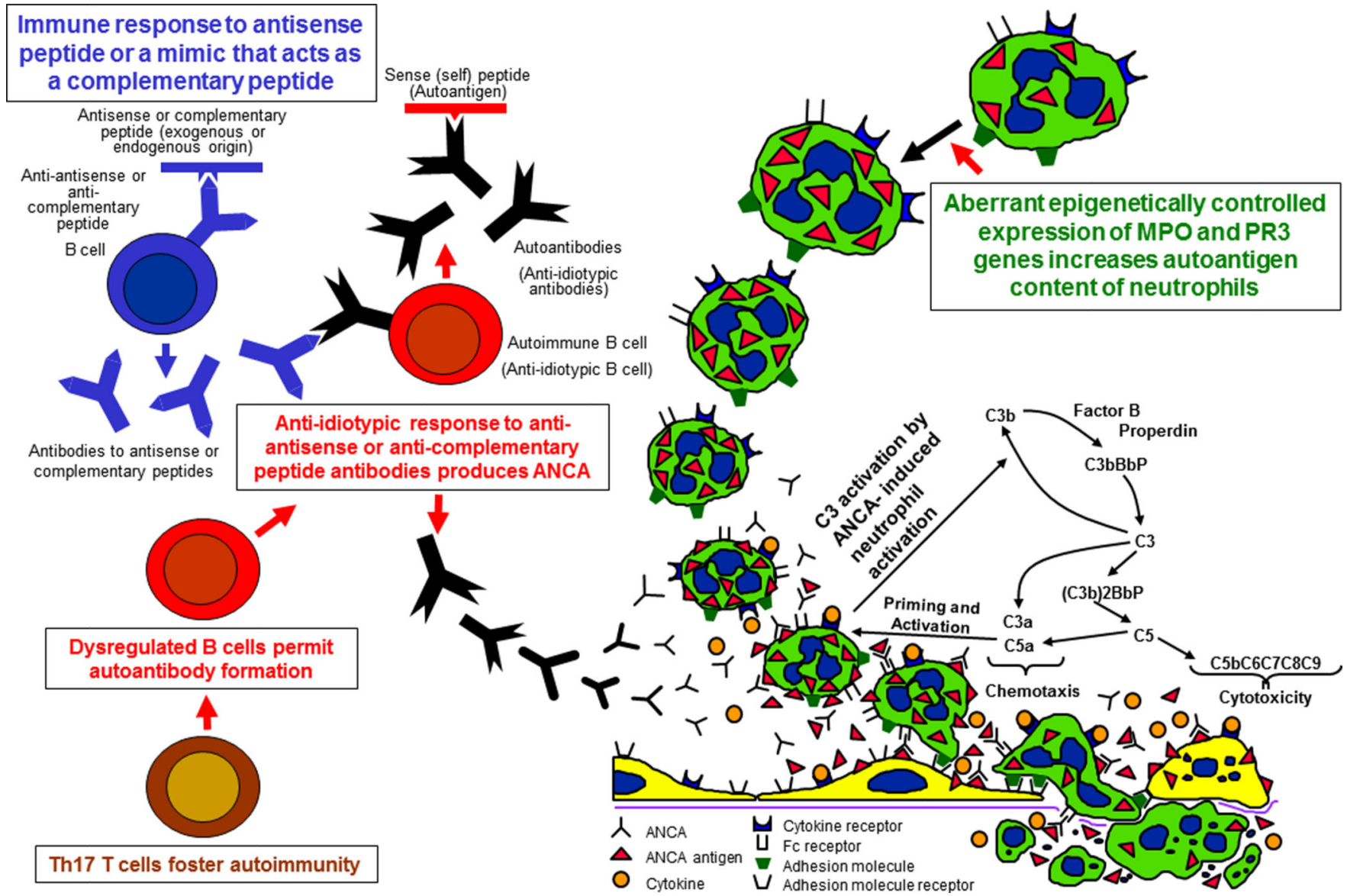

Figure 1. Immunogenesis and pathogenesis of ANCA disease

Diagram of putative events in the pathogenesis of ANCA disease based on in vitro and in vivo experimental observations. In the upper left, the theory of autoimmunity induced by an immune response to a complementary peptide is depicted. The lower left proposes that $\mathrm{T}$ cell regulation is disturbed to allow persistence and progression of autoimmunity. In the upper right, the aberrant increased production of ANCA antigens by epigenetic dysregulation of gene expression is illustrated. Once ANCA antibodies are present along with neutrophils with increased antigens, the sequence of pathogenic events illustrated in the lower right can occur, i.e. cytokines or other priming factors induce neutrophils to express more ANCA antigens at the cell surface where they are available for binding to ANCA, which activates neutrophils by both Fc receptor engagement and Fab'2 binding. Factors released by neutrophils activate the alternative complement pathway, which generates factors that amplify recruitment and activation of neutrophils. Activated neutrophils release toxic factors that cause inflammatory injury to endothelial cells and vessel walls.

(Reproduced with permission of J.C. Jennette) 